\title{
The affective notes of represented space as motors of emotional and sensorial response
}

\author{
Elisa Morselli ${ }^{1, *}$ \\ ${ }^{1}$ Sapienza University of Rome, Department of Architecture and Design, Via Flaminia 359, Rome, \\ Italy
}

\begin{abstract}
The following essay proposes to investigate the perceptual and emotional aspects related to the visualization of architectural images. The field of research is limited to a well-defined category: figurative representations as the photographic and digital images of contemporary architecture. In particular, two types will be analysed: the un-built architecture produced by Studio MIR and Bloomimages compared with the photographed built architecture. Using figurative images as a tool of reading, the aim of this work is to identify and classify three types of affective spaces capable of generating a specific kind of perception, producing a sensorial classification of atmosphere for architecture. The study of the Psychology of Art, as well as Aesthetics and Neuroaesthetics can be a valuable tool in understanding the phenomena of the present, considering the marked pictoriality of these images. The application of the analytic methodology, developed in these disciplines, can suggest a new way of "looking" at the project, paying attention to the representation of the atmospheres, which characterizes the experience of felt space. Keywords: Affective Space, Perception, Representation, Aesthetics, Atmospheres, Design Research, Generators.
\end{abstract}

\section{Introduction}

The research moves from a consideration on the current condition: in the graphic apparatus of architectural design, today more than ever, the focus is shifted towards the processing of image-effects that aim to attribute "affective" qualities to the space. In other words, contemporary architectural images, like works of art, through the increment of painterly aspects are intended to stimulate in the observer a bodily and emotional response that influences the perceived subject regardless of the intrinsic qualities of the presented work.

Consistently with the current philosophical debate led by the German phenomenologist Gernot Böhme, it is possible to see how the aesthetic mark of contemporary images tries to evoke the "felt" atmosphere of lived space [1]. To produce this feeling in images, architecture is never shown in isolation, it is instead restored to the multiplicity and at the same time to the transience of the phenomena that characterise the reality of the world. This means to pay

*Corresponding author: elisa.morselli@uniroma1.it 
attention to the flow of time, changing seasons and meteorological conditions, as well as the presence of people and objects that animate the scene.

In the last ten years, the need to excite the viewer emotionally and sensorially has led figurative representations towards a morphing from clear to indeterminate. The goal to pursue is no longer to depict architecture cleanly, making every detail readable. Both photographers and renderers are moving away from photorealistic references: through an overlap of filters they "dirty" the image, restoring the perception of lived space. In succession, I will describe three categories of affective space, focusing on the emotional and sensorial perception of the atmosphere presented.

\section{The representation of Clear Space}

To better understand the issue, let us start by analysing the first category with two images showing different architectural solutions (a staircase and a ramp) for exhibition spaces.

Both these architectural elements, if we limit ourselves to providing a purely technical description, can be described as "transit space" designed to overcome a difference in height. From an architectural point of view these elements could be realized with infinite solutions: the only permanent feature is given by the bodily sensation that can be experienced in this "space of movement". The vertical shift, obtained by means of ascent and descent, qualifies this element in every project, regardless of the type or intended use. By observing the two images of different projects by different authors, it is evident how this motion is central to both representations and how it is generated by means of different devices that can be compared to each other.
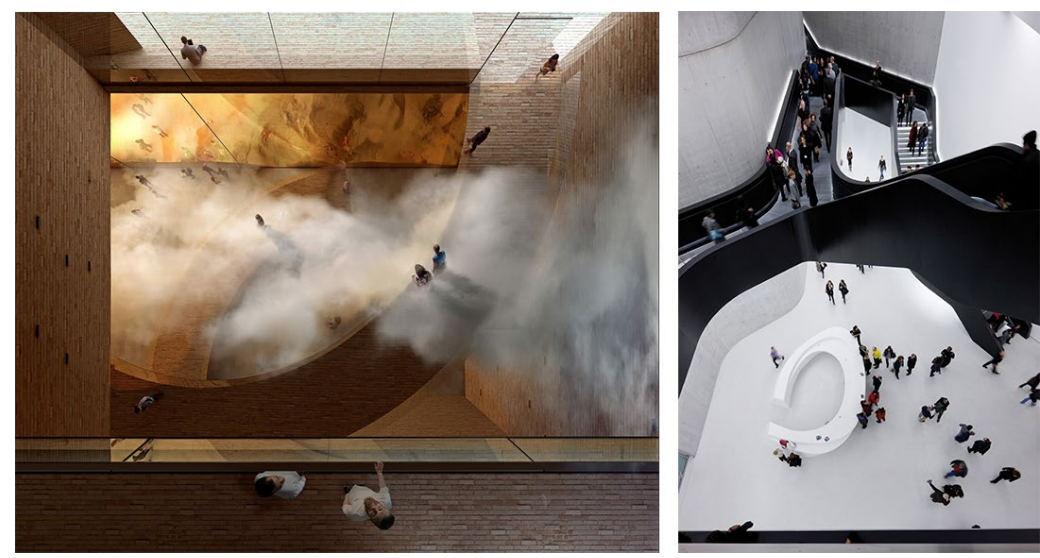

Fig. 1. Digital Image by Mir, Asif Khan Architect, Pavilion Expo Dubai 2020 (C Mir)

Fig. 2. Photo by Iwan Baan (2009), Zaha Hadid Architects, Maxxi Museum, Rome (C Iwan Baan)

The first expedient is identifiable in the perspective structure of the images. The simulated ocular direction proceeds from top to bottom, "sucking" the observer into the space funnel [2]. Due to the observer's location, the gaze opens up in correspondence with the great central void around which the staircase is articulated, thus generating a sensation of vertigo. Through the loss of balance, we actively act on observer's perception of movement: in both images, the eye, through the camera, is placed at the top level, projecting as far as possible from the safety balustrade. While in the second picture you can still see the border, in the first one the tension is greater: the area coinciding with the observer's eye is placed zenithally 
outside the parapet. By assuming an unrealistic position, the sensation of vertigo is increased by simulating a suspension on an inaccessible level. The effect generated by this type of perspective structure can be compared to the illusion produced by the perspective "from below up", widely used during the eighteenth century for ceilings and vaults frescoes. In the frescoes, a whirling combination of architectural elements and moving figures leads the observer's eye towards the centre in the space where the sky opens. Usually, this technique uses fake architectural structures that disappear in a naturalistic background (often a sky) so as to give the illusion - by means of the depth of the perspective system - of a dematerialized covering.
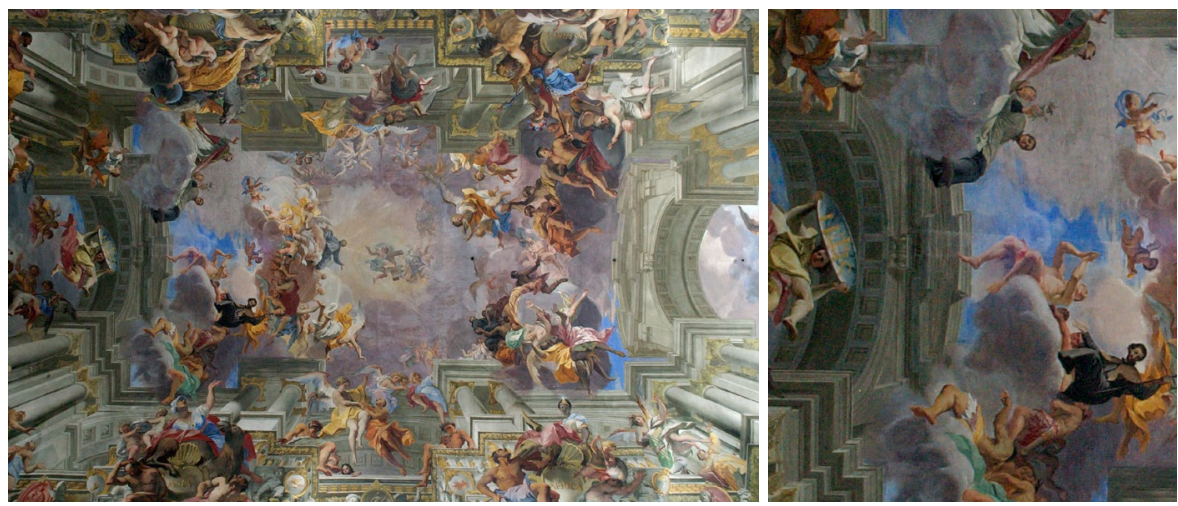

Fig. 3. Andrea Pozzo, Gloria di Sant'Ignazio fresco, Rome, (1691-1694) and characters details

Furthermore, the effect obtained by this perspective implant is amplified by the sensations generated in the observer by means of the embodied simulation mechanisms. Vittorio Gallese's and David Freedberg's studies demonstrated that these mechanisms are activated in spectators even by the vision of static images: "when the actions, emotions and sensations perceived are depicted". [3]

The representations of sensorimotor activity and emotions have therefore great importance to describe an ambiance. In the first image of the ramp (Fig. 1), the feeling of vertigo is generated by the characters leaning forward and looking down, capturing the depth of the space in height, while the character in the foreground is looking up towards an indefinite point, extending the depth of the space towards the sky. Through this performance of corporeal imbalance, the observer is pushed to sensorially grasp the depth of the space. Furthermore, there is a direct ocular contact between the eye of the first man at the top and the eye of the observer over the screen, just like the figures depicted in the Baroque vaults. Differently, in the second image examined (Fig. 2), the motion is generated by people continuously walking through the stairs space.

The images show numerous affinities producing a precise narration of space. In both of these (un-built and built architecture), the need of generating the bodily and sensorial experience of lived space is central. However, again observing the first one image, it is possible to grasp another important detail: the perception of vertical movement is accentuated by the introduction of an artificial "fog" that crosses the great void of the ramp, invading its entire height and overcoming the top edge of the photo. Expanding and contracting in an uncontrolled manner the fog generates a "widespread" movement that "touches" characters and architecture at the same time, dirtying the image. With the introduction of this particular the representation begins to break away from the photo-realistic contacts. The first image is a rendering elaborated by the Norwegian studio MIR for Asif Khan, taking part in 2020 Expo 
Competition in Dubai. The second image shows the interior stair of the Maxxi Museum in Rome designed by Zaha Hadid Architects, photographed by Iwan Baan in 2009.

\section{The representation of Ambiguous Space}

The second category concerns the representation of ambiguous space. Starting from this category, the analogies between built and un-built architecture become more blurred. This splitting is more evident for the outdoor stage, where the description of meteorological phenomena becomes artificial to increase the observer's involvement. The manipulations of colour and light effects are in line with the current trends of urban design projects. The urban planner and sociologist Jean-Paul Thibaud highlights how nowadays the aim of designers is no longer limited to the formal definition of the spatial elements, but rather extends to install an "atmospheric" space capable of transforming the perception of architecture by acting on its inhabitants [4]. The goal is to offer a sensory and emotional experience. This need has led representation techniques to acquire strong effects of light and colour, to simulate extreme weather conditions, stimulating the observer's emotional response. In digital representations, by exploiting the software's potential, the natural atmospheric conditions are altered to evoke extreme and extended meteorological phenomena, while they generally continue to be sought in photography. Most photographers work using ideal lighting conditions - clear and sunny skies - that highlight architectural features.

The outdoor images of Hamburg's Elbphilharmonie by architects Herzog \& de Meuron are particularly appropriate to illustrate this aspect. The two photos below depict the main front of the building taken from a dock port. The building project is part of a large-scale urban redevelopment operation (HafenCity), launched to develop the waterfront of Hamburg. The new Elbphilharmonie is grafted onto a pre-existence - the deposit of Werner Kallmorgen - and occupies a privileged position: it stands on the terminal end of the tongue of land between the Sandtorhafen and the Grasbrookhafen. This location coincides with HafenCity's sea entrance and, therefore, the Philharmonic becomes the landmark of the new district.
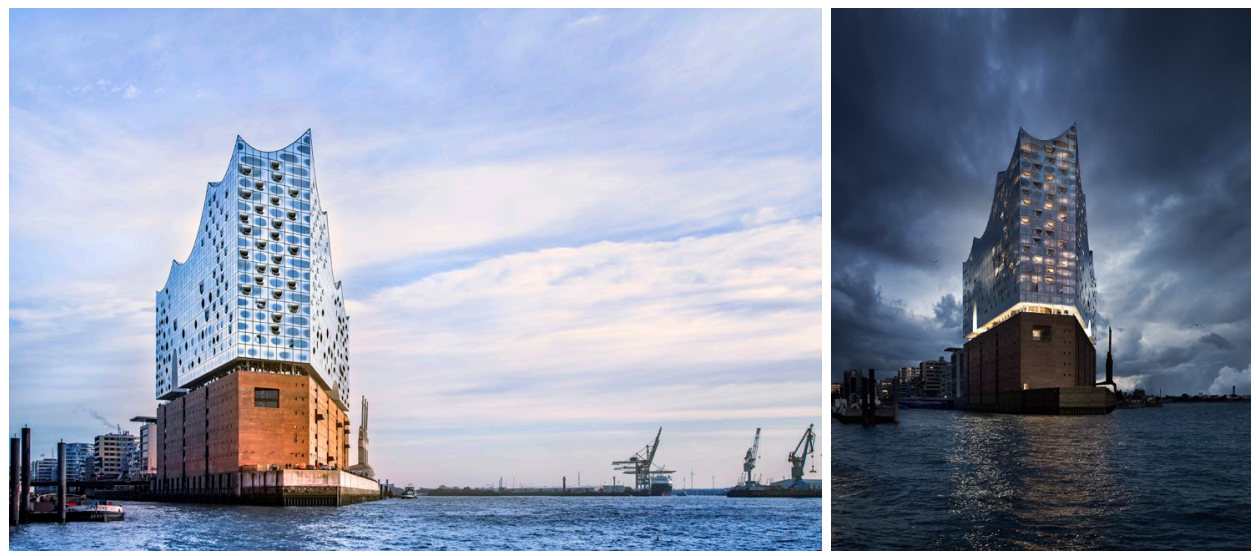

Fig. 4. Photo by Thies Rätzke (2017), Herzog \& de Meuron Architects, Elbphilharmonie of Hamburg, Elbphilharmonie (CThies Rätzke

Fig. 5 Rendering by Bloomimages (2007), Herzog \& de Meuron Architects, Elbphilharmonie of Hamburg, OBloomimages

Reading from left to right, the first image (Fig. 4) is a shot taken by Thies Rätzke in 2017, while Fig. 5 is rendering made by Bloomimages ten years earlier. Starting from the 
description of the image's structure it is possible to note many affinities: both the photographer and Bloomimages adopt the same position, simulating a shot from the dock to the side of the Philharmonic. In the first image - Rätzke's photo - the building envelope reflects "normal" lighting conditions, while in the digital image the background undergoes increasing changes. In the digital representation (Fig. 5), the sky becomes cloudier assuming dark blue colours. In that night setting, a sky full of clouds is reflected on the building and the sea. The gloaming cloudy sky generates a feeling of excitement on the viewer, and increases the tension induced by the formal solution of the building. The taut curves of the envelope's upper part are enhanced by the colour contrast; the Philharmonic is framed by a white glow. By this artifice, there is a simulation of movement that interacts with the observer's corporal perception. In an article on colour perception, neuroscientist Vittorio Gallese states that when there is "a sudden chromatic jump [it] stimulates a sensation of movement and physical change of position. [...] It is, in fact, known that one of the visual features of low level that influence the perception of movement is colour" [5]. Moreover, the apparent movement induced by the colour's nuances accentuates the emotional character of the image. German psychologist Rudolf Arnheim, has already identified this perceptual mechanism in the late 1960s. In Art and Illusion, he writes that "all colour gradients have the power to create depth, but among them the gradients of brightness are the most efficient" [6]. This explains again how the perception of movement is activated in the observer. Regarding this expedient, Arnheim reminds us that this kind of illusion has been widely used by the artists of the Nineteenth century. Romantic painters "represented the sum of local brightness, local colour, and the brightness and colour of the illumination through a single shade of pigment. [...] This pictorial procedure also defined the individual as being partly the creature of its environment, subject to influences that cannot simply be shed like veils" [7].

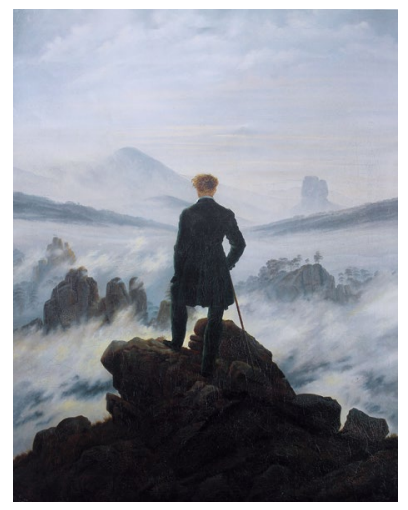

Fig. 6. Caspar David Friedrich, Wanderer above the Sea of Fog (1818), Kunsthalle Hamburg

Today these concepts are more current than ever. Since as Jean Paul Thibaud argues, the landscape representation is no longer limited to a "natural" analysis of the context but focuses on an artistic representation. Likewise, Thibaud quotes Romantic painters, in this case to underline the feeling involved in this artistic production: "is the idea of Stimmung that neatly expresses the intrinsic relationship between the perceptible unity introduced by the landscape and its constitutive feeling" [8].

\section{The representation of Indeterminate Space}

In the final category, the artificial manipulation on the environment is dominant. The alterations on colour and light describing the ambiance are not limited to the background; 
instead they invade the entire space of the image, overlapping the architecture. In this way, interpreting Thibaud's thinking, making all the components present in the space work together and "integrating them by giving the same tonality to all that appears" [9], the true essence of ambiance becomes visual reality. "As we may learn from the art world, working on sensory matter consists in giving the world a singular face, a certain overall physiognomy, a particular colour scheme." [10]

In the digital image analysed below, the need to homogeneously characterize the ambiance translates into a visual effect of rarefaction with a predominant tone of colour. For the observer, due to this effect it is difficult to recognize every single element and its spatial arrangement. As in William Turner's work Norham Castle (Fig. 7), where the blinding pure colours express the light while the historic building and landscape merge together; in the digital representations, the background, the work, and its inhabitants are all given the same shade and therefore affective tone. Using a definition formulated by the historian Robert $\mathrm{J}$. Pepperell: "visual indeterminacy can be defined, as the perceptual experience occurring in response to an image that suggests the presence of objects but denies easy or immediate recognition" [11].
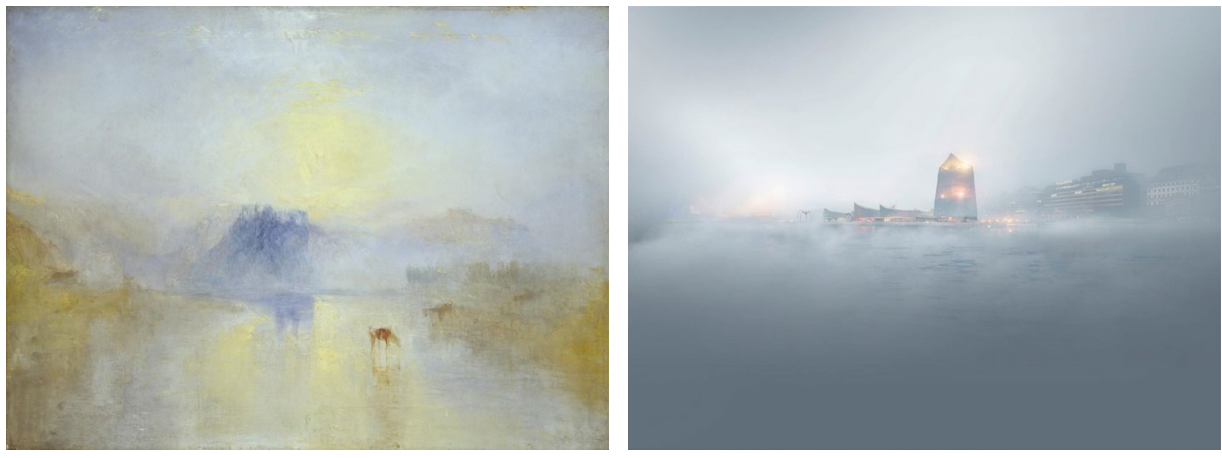

Fig. 7 J. M. William Turner, Norham Castle Sunrise (1845), Northumberland

Fig. 8 Moreau Kusunoki Architects, Digital image (2014), Guggenheim Helsinki Museum, (C) Moreau Kusunoki Architects

According to Pepperell, the indeterminate category can be effectively described by means of a single digital image: an external view of the winning project for the Guggenheim Helsinki Design Competition in 2014, by Moreau Kusunoki Architects (Fig. 8).

Beginning with the analysis, let us imagine asking an observer to describe what they see without giving them any information about that representation. The observer in question would certainly feel lost, experiencing difficulties in recognizing both the elements of the composition and their position. The landscape appears, indeed, entirely wrapped in a dense grey-blue fog; the presence of some light points guides the eye in the distance, allowing the part of inhabited space to be sensed. The cold colours together with the widespread fog could suggest a Nordic landscape. The elements of the context - the surrounding buildings, the sky and the sea - are hinted, but not clearly distinguishable from each other. Some elements allow the observer to recognize the presence of a large building: it is possible to perceive the height differences of the volume and the curves on the roof, but it is equally difficult to add anything else.

In this image, the only readable element is a variation of chromatic tonality that extends spatially in every direction: it describes an affective tone. To explain this effect, we can use 
the definition of actual fact, formulated by Josef Albers at the end of the 1960s [12]. Gernot Böhme - who reminds us that the goal in Albers' colour research was not to represent anything, but to put on stage a chromatic fact - took up this concept. Albers, following the experiments conducted in Homage in the square, distinguished the factual fact, that is the colour physically spread on the canvas, from the actual fact that is the perceived colour, the thing in act: "which cannot be located on the canvas or on the single places, being rather in a certain sense an excitation of the perceptual space in which the observer comes in when dealing with the painting" [13].

The tone of this image generates various perceptual aspects. Firstly, the grey-blue fog is able to generate a bodily sensation, by means of synesthesia it is possible to perceive cold and humidity on the skin. Secondly, the warm lights and bright colours catch the attention of the observer, generating a corporeal sensation related to heat. Furthermore, the image as a whole generates movement. The represented environment thus acquires a strong dynamism because the observer, unable to recognise the elements, is forced to explore it visually. In this image, it is indeed difficult to clearly understand the museum's spatial position: the ground is not perceptible, just as it is not possible to understand the connection with the sea since the pier is immersed in the fog. The museum is depicted from a considerable distance, and due to the positioning of the camera the observer is placed at the centre of an indeterminate space. In this way, a growing desire to reach the only inhabited place identifiable in the image thanks to the light - is produced. The observer is doubly stimulated: the subject's imagination makes an effort to analyse space - performing an analytic function on the recognition of the elements present - and at the same time bodily sensations are produced.

\section{Conclusions}

The goal of these images is to excite the observer's sensorial experience: the representation of fogs and particular weather conditions stimulates hearing, smell and touch as well as the representation of air movement stimulates the tactile sense of humidity and temperature. These ambiance qualities are generated in observatories not only with the insertion of people and objects, but primarily with slight shades of colour blurring the image. In this sense, it is possible to argue that the representation of lived space is undergoing a morphing from clear to indeterminate.

To underline the atmosphere of the lived space, these images propose to simulate not only architectural shapes, but rather the contingency of its appearance. The aesthetic features are not limited to the anticipation of the perception of a solid body in space; but instead to the stimulation of an emotional response. Consequently, the narration of ambiance is the true representation's subject. Architecture is a vital part in this context; it is a living character that vibrates together with its inhabitants, the changing of the seasons and the passing of the day. Welcoming the contingency of life means to strip the architecture of its idealism, to bring denser aspects potentially more imprecise and therefore truer. It means making architecture more hypothetical, pictorial, imaginative and paradoxically more real, enabling it to evoke the affective and sensory experience that characterizes every day urban life.

\section{References}

1. G. Böhme, Atmospheric architectures: the aesthetics of felt spaces, Bloomsbury Publishing (2017) 
2, 6. R. Arnheim, Art and visual perception, Univ. of California Press (1974)

3. V. Gallese, Arte, corpo, cervello: per un'estetica sperimentale, Micromega, 2, 49-67 (2014)

4, 8-10. J. P. Thibaud, The backstage of urban ambiances: when atmospheres pervade everyday experience, Emotion, space and society, 15, 39-46 (2015)

5. V. Gallese, M. Ardizzi, Il senso del colore. Tra mondo, corpo e cervello, Colori: l'emozione dei colori nell'arte, Milano: Silvana Editoriale, 23-35 (2017)

11. R. Pepperell, Connecting art and the brain: an artist's perspective on visual indeterminacy, Frontiers in human neuroscience, 5, 84 (2011)

12. J. Albers, Interaction of color, Yale University Press (2006)

13. G. Böhme, Atmosfere estasi e messe in scena: l'estetica come teoria generale della percezione, Milano: Marinotti (2010)

\section{Bibliography}

R. Arnheim, Art and visual perception. Univ. of California Press (1974)

J. Albers, Interaction of color. Yale University Press (1971)

G. Böhme, The aesthetics of atmospheres (J.-P. Thibaud, Ed.) (1 ed.). London; New York: Routledge (2016)

G. Böhme, Atmosphere as the fundamental concept of a new aesthetics. Thesis eleven, 36(1), 113-126 (1993)

A. Damasio, Descartes' error: emotion, reason, and the human brain. New York: G. P. Putnam (1994)

D. Freedberg, V. Gallese, Motion, emotion and empathy in aesthetic experience. Trends in cognitive sciences, 11, 5, 197-203 (2017)

D. Freedberg, The power of images: Studies in the history and theory of response, Chicago: University of Chicago Press (1989)

V. Gallese, V. (2014). Arte, corpo, cervello: per un'estetica sperimentale. Micromega, 2, 4967 (2014)

V. Gallese, Bodily selves in relation: embodied simulation as second-person perspective on intersubjectivity. Phil. Trans. R. Soc. B, 369(1644), 20130177 (2014)

T. Griffero, Atmospheres: aesthetics of emotional spaces. Routledge (2016)

D. Leatherbarrow, Atmospheric condition. Phenomenologies of the city: studies in the history and philosophy of architecture, M. Sternberg \& H. Steiner Eds., 85-99 (2015)

J. P. Thibaud, The backstage of urban ambiances: When atmospheres pervade everyday experience. Emotion, space and society, 15, 39-46 (2015)

J. P. Thibaud, The sensory fabric of urban ambiances. The senses and society, 6, 2, 203-215 (2011).

D. Vesely, Architecture in the age of divided representation: the question of creativity in the shadow of production, MIT press (2004).

S, Vizzardelli, Verso una nuova estetica: categorie in movimento, Milano: Mondadori (2010)

S. Zeki, J. Nash, Inner vision: an exploration of art and the brain, 415, Oxford: Oxford University Press (1999)

\section{Acknowledgments}

I would like to thank the following for their kind permission to reproduce their images: Mir for the rendering of the Pavilion Expo in Dubai (Asif Khan Architect), Iwan Baan for the interior's photograph of Maxxi Museum, Herzog \& De Meuron for the images of 
Elbphilharmonie of Hamburg and Moreau Kusunoki Architects for the rendering of Guggenheim Helsinki Museum Competition. 